\title{
Quantitative relation between gastric acid secretion and changes in urinary acid excretion
}

\author{
C D Johnson, P A Harris, C Wastell
}

\begin{abstract}
This study was designed to investigate the relations between gastric acid secretion and alkalinisation of the urine. Normal subjects underwent standard pentagastrin $(6 \mu \mathrm{g} / \mathrm{kg})$ $(n=5)$ and sham feeding $(n=6)$ tests, with additional collection of urine samples before and two and three hours after the start of the test for measurement of titratable urine acidity. Nine subjects provided urine before and two hours after a test meal. Sham feeding $(n=5)$ and meal $(n=6)$ tests were carried out in patients who had had a successful vagotomy for duodenal ulcer. There was a significant correlation of gastric acid response in the standard tests with simultaneous changes in urine acidity $(r=-0.79, p<0.001)$ and also with urine acid output after the test meal, on another day $(r=-0.73 ; p<0.02)$. The correlation was insufficient to predict gastric function from changes in urinary acidity, but there was clear separation of the results in normal subjects and patients with vagotomy. Changes in urine acidity after a standardised meal may prove to be useful as a screening test after vagotomy to select patients who are likely to have a persisting high gastric acid response to vagal stimulants.
\end{abstract}

Tests of gastric function may be used after operation for duodenal ulcer to assess the completeness of vagotomy. Peak acid output (PAO) is measured after the administration of pentagastrin and vagal innervation is assessed by insulin induced hypoglycaemia (Hollander test). ' This may be unpleasant for the subject, and is potentially dangerous. ${ }^{2}$ The sympathetic nervous system ${ }^{3}$ and the pituitary-adrenal axis ${ }^{4}$ are also aroused, which may lead to myocardial infarction, fits, and even death. ${ }^{56}$

Sham feeding, a pure physiological vagal stimulus, has been proposed as a safe alternative to the Hollander test.' ${ }^{7}$ Sham feeding can be used to assess completeness of vagotomy, ${ }^{8-10}$ and is as discriminating as insulin hypoglycaemia. ${ }^{10}$ Sham feeding, however, requires nasogastric intubation for gastric aspiration, which is unreliable ${ }^{11-13}$ and unpleasant for the patient. There is a need for an alternative simple and reliable assessment.

During secretion of acid by the gastric mucosa bicarbonate diffuses from the parietal cell into the blood. ${ }^{14}$ This reduces the metabolic acid load normally excreted in the urine, and may lead to alkalinisation of the urine. This postprandial alkaline tide is well known, and its persistence after vagotomy has been proposed as a test of the completeness of denervation. ${ }^{15}$ That study examined only changes in urinary $\mathrm{pH}$ in response to a meal. These changes were not compared with standard tests of gastric function, and no attempt was made to quantify changes in urinary acid secretion. Buffers present in urine may reduce variation in $\mathrm{pH}$ despite changes in acid load.

The present study attempted to quantify changes in urine acid excretion and to relate them to changes in gastric acid secretion. Furthermore, we investigated whether urine acid excretion might be useful as a measure of gastric acid responses to a meal, without nasogastric intubation, in normal subjects and in patients after vagotomy.

\section{Patients and methods}

Gastric secretion and urinary acid output were measured in fourteen normal men volunteers aged 17 to 46 years and seven men patients aged 27 to 75 years who had previously had a vagotomy as treatment for a duodenal ulcer: selective gastric vagotomy four (three with antrectomy); highly selective vagotomy three (one with pyloroplasty). One patient had a recurrent duodenal ulcer after highly selective vagotomy. Studies were performed a median of 13 years after vagotomy (range 5.5-16 years). The project was approved by the local ethical committee, and all subjects gave informed consent.

Subjects were asked not to eat, drink, or take any drugs from midnight on the day of the test. One patient was taking $\mathrm{H}_{2}$ receptor antagonists for recurrent ulcer, but this treatment was stopped 48 hours before the test. On waking, all subjects emptied their bladder by voiding. The time was recorded and the urine was discarded.

\section{COLLECTION OF SAMPLES AND CHEMICAL}

\section{DETERMINATION}

Urine samples were collected by voiding directly into glass measuring cylinders. Urinary acid (or base) content was determined using the method of Jorgensen ${ }^{16}$ : a measured volume of urine was acidified with a known volume of hydrochloric acid to liberate carbon dioxide from any bicarbonate present and to dissolve any deposit of phosphate. The mixture was then boiled to drive off the carbon dioxide and after dilution was titrated to $\mathrm{pH} 7 \cdot 4$ with sodium hydroxide $(0.1 \mathrm{M})$ in the presence of formaldehyde. This determination was done within two hours of voiding to prevent changes in titratable acidity secondary to evaporation of carbon dioxide from the sample.

Gastric secretion was collected by nasogastric intubation after application of lignocaine spray (3\%) to one nostril and the pharnyx. A double lumen gastric tube ${ }^{17}$ was passed into the stomach 
and the resting juice was aspirated. The position of the tube was assessed by an adaptation of the water recovery test": $250 \mathrm{ml}$ of water was instilled through the tube and aspiration was attempted immediately. If more than $225 \mathrm{ml}$ was recovered the tip of the tube was assumed to be in a satisfactory position in the stomach for gastric aspiration. During the test continuous low pressure aspiration was applied to the tube, with the second lumen open to allow flow of air through the system.

Samples were collected in consecutive 15 minute periods and the volume was measured directly. After centrifugation to remove mucus and debris, the acid content of an aliquot was measured by titration to $\mathrm{pH} 7$ with $0-1 \mathrm{M} \mathrm{NaOH}$ using an automatic $\mathrm{pH}$ unit and burette (PHM 62 standard $\mathrm{pH}$ meter, TTT 60 titrator, ABU 11 autoburette, TTA 60 titration assembly; Radiometer, Copenhagen, Denmark).

\section{PROTOCOLS}

Four studies were carried out. Firstly, in six normal subjects changes in urine acidity in the fasting state were determined by the collection of three urine samples. A basal specimen was obtained at a known time after early morning voiding. One hour later, $300 \mathrm{ml}$ of water was given by mouth. Urine samples were collected two and three hours after the basal sample.

Secondly, gastric and urine acid outputs in response to pentagastrin were measured in five normal subjects. After two basal collections of gastric juice, pentagastrin $6 \mu \mathrm{g} / \mathrm{kg}$ was given subcutaneously. Gastric juice was collected for four 15 minute periods. The nasogastric tube was removed and $300 \mathrm{ml}$ of water was given by mouth. Urine samples were collected before and two and three hours after the administration of pentagastrin.

The responses to sham feeding were determined in six normal subjects and six patients after vagotomy, using the chew and spit technique. ${ }^{10}$ After two basal collections of gastric juice, sham feeding was carried out for 10 minutes. The test stimulus was toast and marmalade (two slices of bread $(60 \mathrm{~g}), 10 \mathrm{~g}$ of butter, and $20 \mathrm{~g}$ of marmalade), freshly prepared in a room remote from the subject. Each subject was asked to take bites of the toast and to taste, chew, and enjoy them, then spit them out into a spittoon. The mouth was rinsed with water between mouthfuls. Gastric juice was collected in 15 minute fractions for one hour following sham feeding. The nasogastric tube was then removed and a $300 \mathrm{ml}$ water load was given by mouth. Urine samples were collected just before sham feeding and two and three hours after the start of sham feeding.

The fourth protocol measured changes in urinary acidity after a standard meal. Basal urine was collected from nine normal and six postvagotomy subjects. Each subject ate a standard meal comprised of two cheese and tomato sandwiches consisting of two slices $(60 \mathrm{~g})$ of brown bread $(8 \cdot 9 \mathrm{~g} / 100 \mathrm{~g}$ protein, $2 \cdot 2 \mathrm{~g} / 100 \mathrm{~g}$ fat, $44 \cdot 7 \mathrm{~g} /$ $100 \mathrm{~g}$ carbohydrate), $50 \mathrm{~g}$ of cheddar cheese (26 $\mathrm{g} / 100 \mathrm{~g}$ protein, $33.5 \mathrm{~g} / 100 \mathrm{~g}$ fat), and one tomato ( $0.9 \mathrm{~g} / 100 \mathrm{~g}$ protein, $2.8 \mathrm{~g} / 100 \mathrm{~g}$ carbohydrate); three plain digestive biscuits $(9.8 \mathrm{~g} / 100 \mathrm{~g}$ protein, $20.5 \mathrm{~g} / 100 \mathrm{~g}$ fat, $66 \mathrm{~g} / 100 \mathrm{~g}$ carbohydrate); one apple $(0.3 \mathrm{~g} / 100 \mathrm{~g}$ protein, $11.9 \mathrm{~g} /$ $100 \mathrm{~g}$ carbohydrate); and two glasses of water. A further urine sample was collected two hours after the start of the meal.

\section{CALCUlations}

Peak gastric acid responses (PAO) to sham feeding $\left(\mathrm{PAO}_{\mathrm{SF}}\right)$ and pentagastrin $\left(\mathrm{PAO} \mathrm{PG}_{\mathrm{PG}}\right)$ were calculated by doubling the sum of the two highest 15 minute outputs. Total acid output (TAO) was the sum of acid outputs to sham feeding $\left(\mathrm{TAO}_{\mathrm{SF}}\right)$ or to pentagastrin $\left(\mathrm{TAO}_{\mathrm{PG}}\right)$ in one hour.

Urinary acid output was expressed as amount excreted per hour. A negative value represented net excretion of base. Changes in urinary acid outputs were expressed as the difference between the rate for each sample and the preceding basal rate. If the urine had become less acid (more alkaline), these values were given a negative sign.

Statistical analysis was with least squares regression analysis for correlations between the gastric and urinary outputs. The Wilcoxon rank sum and signed rank tests were also used to compare similar variables in the same and different groups respectively. Probabilities less than 0.05 were said to be significant.

\section{Results}

FASTING SUBJECTS

There was no change in urinary acid outputs during the three hours' observation (Fig 1).

\section{PENTAGASTRIN}

Response to pentagastrin was measured in five normal subjects; the median (range) of $\mathrm{PAO}_{\mathrm{PG}}$ was $32 \cdot 3(16 \cdot 7-61 \cdot 8) \mathrm{mmol} / \mathrm{h}$ and of $\mathrm{TAO}_{\mathrm{PG}} 27 \cdot 6$ $(12 \cdot 9-38 \cdot 7) \mathrm{mmol} / \mathrm{h}$. Urinary acid output fell at both two and three hours after pentagastrin (Fig 1). This alkalinisation of the urine occurred in all

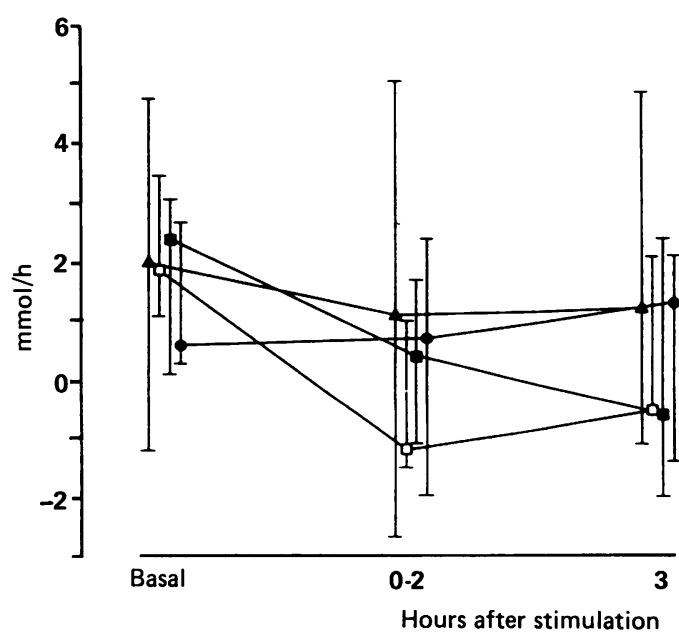

Figure 1: Urine acid outputs under basal conditions in fasting normal subjects $(\mathbf{\Delta})$ and after stimulation of gastric acid secretion with pentagastrin ( $\square$ normal subjects) or sham feeding ( normal subjects; vagotomy patients). Median values and ranges. 


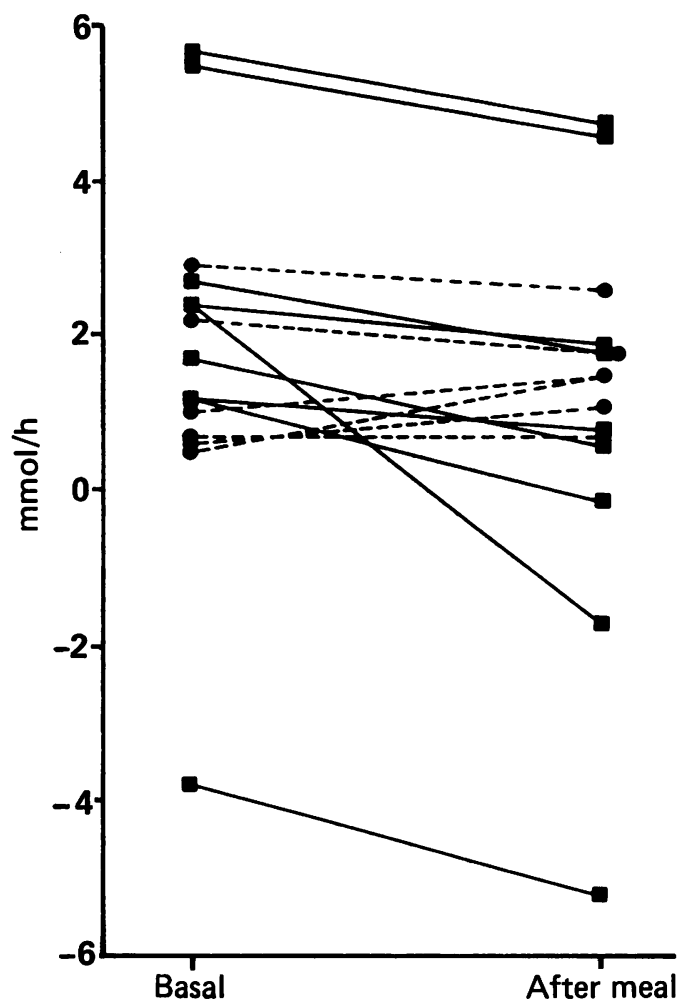

Figure 2: Urine acid output before and after a standard meal in normal subjects (-

subjects and was significantly different from the variable changes seen in fasting subjects.

\section{SHAM FEEDING}

In normal subjects, sham feeding stimulated gastric acid output to a lesser extent than pentagastrin. The median (range) $\mathrm{PAO}_{\mathrm{SF}}$ was 8.6 $(6 \cdot 1-17 \cdot 9) \mathrm{mmol} / \mathrm{h}$ and $\mathrm{TAO}_{\mathrm{SF}} 6 \cdot 3(4 \cdot 8-14 \cdot 2)$ $\mathrm{mmol} / \mathrm{h}$. Urine acid excretion fell after sham feeding (Fig 1). The value at three hours was significantly less than the basal rate, and the change from the basal rate was greater than the change seen in the third hour of observation of fasting subjects $(\mathrm{p}<0.01)$.

One patient after vagotomy had evidence of incomplete vagotomy $\left(\mathrm{PAO}_{\mathrm{SF}} 22.5 \mathrm{mmol} / \mathrm{h}\right) . \mathrm{He}$ subsequently had surgery for recurrent duodenal ulcer. In patients with complete vagotomy (defined as $\mathrm{PAO}_{\mathrm{SF}}<7 \mathrm{mmol} / \mathrm{h}^{10}$ ), the median (range) $\mathrm{PAO}_{\mathrm{SF}}$ was $0.6(0.2-3 \cdot 7) \mathrm{mmol} / \mathrm{h}$ and $\mathrm{TAO}_{\mathrm{SF}} 0 \cdot 2(0-2 \cdot 4) \mathrm{mmol} / \mathrm{h}$.

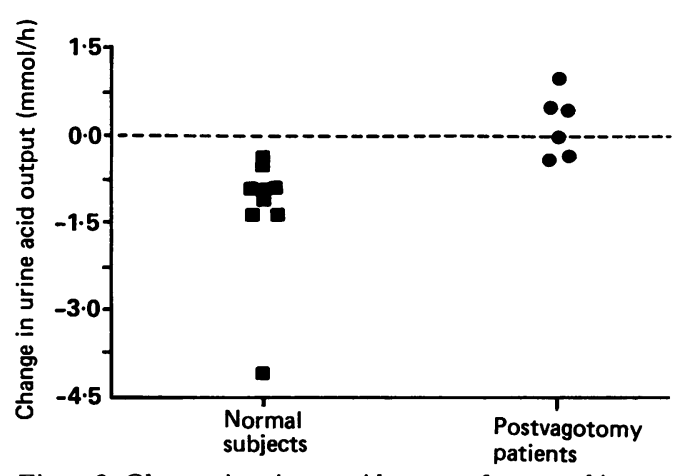

Figure 3: Changes in urinary acid output after a meal in normal subjects ( $\square$ ) and after complete vagotomy (O).
The median (range) basal urinary acid output after vagotomy was $+0 \cdot 6(+0 \cdot 3-+2 \cdot 7) \mathrm{mmol} / \mathrm{h}$. Although this appeared to be less than in normal subjects of all other groups $(+2 \cdot 0(-4 \cdot 0-+5 \cdot 5)$ $\mathrm{mmol} / \mathrm{h}, \mathrm{n}=26$ ), the difference was not significant. After vagotomy, the urinary response to sham feeding was no significant change in acid excretion (Fig 1). The change from basal urine acid excretion in the third hour after sham feeding was significantly less in vagotomised subjects than in normal subjects $(-0 \cdot 3(-1 \cdot 8-+0 \cdot 8)$ $\mathrm{mmol} / \mathrm{h} v-1.8(-4.5-0.8 \mathrm{mmol} / \mathrm{h})$, and was no different from the value recorded in the third hour of observation of fasting subjects.

\section{TEST MEAL}

Basal and postprandial urine acid outputs are shown in Figure 2. The urine acid output after a meal was significantly reduced in normal subjects compared to the basal output $(p<0.01)$. This reduction was not seen in patients who had had a complete vagotomy. In each normal subject there was a reduction in the acid content of the urine, although this was not reflected in changes of $\mathrm{pH}$. Median $\mathrm{pH}$ of basal urine in normal subjects was 5.93 (range 5.51-7.72). Two hours after the meal the corresponding values were $6 \cdot 26(5 \cdot 38-7 \cdot 19)$. After vagotomy, pre and postprandial urine $\mathrm{pH}$ was $5.85(5 \cdot 35$ $6 \cdot 57)$ and $5 \cdot 94(5 \cdot 12-6 \cdot 51)$. In neither group was there a significant change in urine $\mathrm{pH}$ after a meal.

In contrast with the response in normal subjects there was no consistent postprandial change in urine acid output after vagotomy (Fig 3). The responses in the two groups were significantly different $(p<0 \cdot 01)$.

\section{CORRELATION BETWEEN GASTRIC AND URINARY \\ ACID OUTPUT}

The relation between TAO after sham feeding or pentagastrin and changes in urinary acid production in the two hours from the start of the test is shown in Figure 4. There was a good correlation $(\mathrm{r}=-0.79 ; \mathrm{p}<0.001)$ between the two values. Figure 5 shows the relation between $\mathrm{TAO}_{\mathrm{SF}}$ and postprandial changes in urine acidity in the same patients when tested on another day. A significant correlation was observed $(r=-0.73$; $\mathrm{p}<0.02$ ).

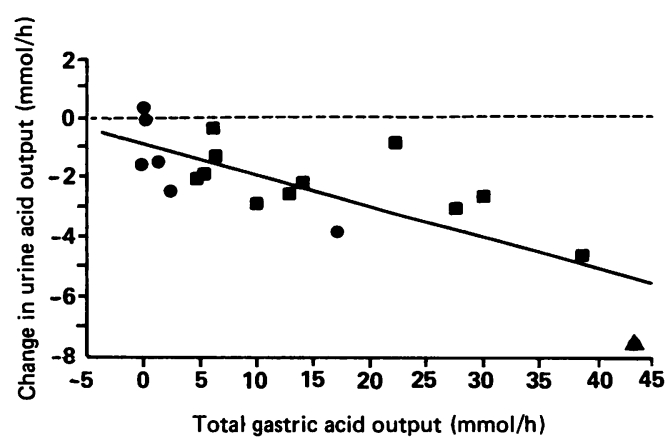

Figure 4: Correlation between changes in urinary acid output and gastric acid output after stimulation with pentagastrin or sham feeding $(r=-0 \cdot 79 ; y=0 \cdot 1 \times-0 \cdot 8 ;$ standard error of estimate of $y=2 \cdot 5$ ). Normal subjects $\square$; complete vagotomy patients $\mathbf{O}$; incomplete vagotomy $\boldsymbol{\Delta}$ 


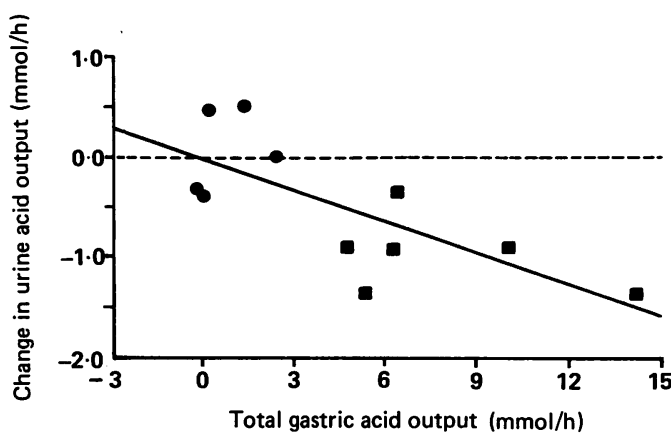

Figure 5: Correlation between changes in urinary acid output after a meal and gastric secretion in response to sham feeding. Tests were performed on different days in the same patients $(r=-0 \cdot 73 ; y=-0 \cdot 1 \times ;$ standard error of estimate of $y=0 \cdot 9)$. Normal subjects $\square$; complete vagotomy patients $\mathbf{0}$.

Similar correlations were seen between PAO and posttest and postprandial changes in urine acidity.

\section{Discussion}

This study was undertaken to investigate the postprandial alkaline tide in normal subjects and its abolition in patients after vagotomy. There is no doubt that a substantial change in the rate of urinary acid output occurs after a meal, although the term postprandial alkaline tide suggests that a net excretion of base occurs. With our test meal, although a reduction in the rate of acid excretion took place, this rarely led to the net excretion of base. The changes could not be detected by measurement of $\mathrm{pH}$ because of the presence of buffers in normal urine.

Basal urinary acid output varied considerably between subjects (Figs 1 and 2). This is related to body weight, previous activity, and previous food intake. To overcome this variability we calculated the changes in output observed during the tests by subtraction of the basal value. A negative change in acid output represents alkalinisation of the urine. The lack of any consistent change during three hours of fasting without stimulation suggests that during the tests any observed changes are indeed due to the test stimulus (Fig 1).

We did not correct for duodenogastric reflux or pyloric losses in the measurement of gastric acid production. Nevertheless, we observed a good correlation between gastric acid output and changes in urine acidity. The measurement of crude TAO and PAO has the advantage of simplicity, and allows us to compare our results with our clinical tests. In common with most published studies we do not compensate for duodenal loss in these calculations. ${ }^{2}$ In the assessment of completeness of vagotomy, infusion of markers is probably unnecessary. ${ }^{10}$

Baron $^{2}$ has reviewed the value of markers for pyloric loss. This probably occurs at a fixed rate, rather than as a constant proportion of gastric secretion, and so failure to correct for such loss will affect the intercepts of the correlation line, but not its slope.

The pentagastrin test enabled us to have higher values for TAO and PAO than could be achieved using sham feeding. This wider range of gastric outputs was reflected in a wider range of changes in urine acid outputs. The correlation between gastric and urine acid outputs appears to hold at all values (Fig 4).

Sham feeding is now the preferred method of assessment of the completeness of vagotomy. ${ }^{210}$ Our method produced values for gastric secretion of about $30 \%$ of those seen after pentagastrin, and of the same order as those observed by others. ${ }^{10}$ In normal subjects, urine acid output fell significantly in the third hour after sham feeding. Nevertheless, the correlation between gastric and urine acid outputs was better in the first two hours after sham feeding.

Sham feeding identified one patient with incomplete vagotomy. Data from this patient were excluded from consideration of the effects of vagotomy but were included in the regression analysis. After successful vagotomy, urine acid output was not altered by sham feeding. This fits with the observed reduction in gastric acid output after vagotomy, and raises the possibility that measurement of changes in urine acidity might be useful as a screening test for completeness of vagotomy. The data shown in Figure 3 suggest that there is minimal overlap between the normal and postvagotomy ranges.

The correlations shown in Figures 4 and 5 show that there is a quantitative relation between gastric acid secretion and the compensatory changes in urine acid output. A true 'alkaline tide,' with $\mathrm{pH}>7$, was not seen in all patients, either during gastric function tests or after a meal. Thus we cannot agree with Ahmad, ${ }^{15}$ who proposed postprandial $\mathrm{pH}$ changes as a simple screening test for gastric function. We found that quantitative assessment of titratable urine acidity gives a more accurate reflection of gastric secretion.

The measurement of changes in urine acidity cannot replace standard gastric function tests as an accurate quantitative measure of gastric acid secretion because the error in predicting gastric function from observation of urinary acid output would be large. Some of this variation may be related to our use of bolus stimulation in the pentagastrin tests, with collection of gastric secretion for one hour. We accept this limitation, because we were not attempting to determine 'true' maximal gastric responses. Rather, we were studying the relation between observed gastric acid output and changes in urine acidity, over a wide range of gastric responses, to our standard gastric function tests in clinical use.

We have shown an inverse linear correlation between gastric secretory capacity, measured by a standard gastric function test, and urine acid production after a meal. In our experiments the urine did not always become alkaline after a meal. After vagotomy, the normal reduction in urine acid excretion after a meal was abolished.

The correlation between gastric acid and urine acid outputs is sufficiently good that changes in urine acid output after a test meal could separate patients with high or low gastric secretion. This could then allow selection of patients for a standard gastric function test, and might avoid such a test in those with postvagotomy abolition of the normal alkalinisation response.

1 Hollander F. The insulin test for the presence of intact nerve fibres after vagal operations for peptic ulcer. Gastroenterology $1946 ; 7: 607-14$ 
2 Baron JH. Gastric secretion tests. In: Nyhus LM, Wastell C eds. Surgery of the stomach and duodenum. Boston: Little, Brown, 1986: 143-63.

3 Cannon WB, McIvor MA, Bliss SW. Studies on the conditions of activity in the endocrine glands XIII. A sympathetic and adrenal mechanism for mobilizing sugar in hypoglycemia. Am F Physiol 1924; 69: 44-66.

4 London J, Wynn V, James VHT. The adrenocortical response to insulin induced hypoglycaemia. $\mathcal{F}$ Endocrinol $1963 ; 27$ : 183-92.

5 Read RC, Doherty JE. Cardiovascular effects of induced insulin hypoglycemia in man during the Hollander test. Am f Surg 1970; 119: 155-62.

6 Stempien SJ. A note on the hazards of maximal insulin testing Gastroenterology 1971; 60: 345-6.

7 Richardson CT, Feldman M. Sham feeding: a safe test for vagotomy. Gastroenterology 1978; 74: 1084.

8 Feldman M, Richardson CT, Fordtran JS. Experience with sham feeding as a test for vagotomy. Gastroenterology 1980 79: 792-5.

9 Athow AC, Sewerniak AT, Barton TP, Levine MR, Clark CG.
Modified sham feeding: a measuring jug ward test for the completeness of vagotomy. Gut 1984; 25: 1152-3.

10 Athow AC, Lewin MR, Sewerniak AT, Clark CG. Gastric secretory responses to modified sham feeding and insulin after vagotomy. $B r \mathcal{F}$ Surg 1986; 73: 132-5.

11 Hassan MA, Hobsley M. Positioning of subject and nasogastric tube during a gastric secretion study. $\mathrm{BrMed} \mathcal{F} 1970 ; \mathrm{i}$ : 458-9.

12 Kyle J, Stephens F. Gastric acidity after duodenal ulcer surgery. Br ₹ Surg 1961; 48: 465

13 Tankel HI, Gillespie IE, Clark DH, Kay AE, MacArthur J. Statistical study of the effect of gastrojejunostomy on human gastric secretion. Gut 1960; 1: 223-9.

14 Ganong WF. Review of medical physiology. Los Angeles: Lange Medical, 1986: 410.

15 Ahmad A. Abolition of postprandial alkaline tide after Ahmad A. Abolition of postprandial alkaline tide after
vagotomy and its use as a screening test in the assessment of vagomy. Br $\mathcal{F}$ Surg 1986; 73:917-9.

16 Varley H, Gowenlock AH, Bell M. Practical clinical biochemistry. London: Heinemann Medical, 1980: 836.

17 Thomson JP, Russell RC, Hobsley M. Double lumen tube fo gastric secretion studies. $\mathrm{Br}$ Med $\mathcal{F}$ 1973; iii: 175. 